\title{
Nocturnal enuresis in patients taking clozapine, risperidone, olanzapine and quetiapine: comparative cohort study
}

\author{
Mira Harrison-Woolrych, Keren Skegg, Janelle Ashton, Peter Herbison and David C. G. Skegg
}

\section{Background}

Nocturnal enuresis has been reported in patients taking clozapine, but the incidence has not been accurately established. The incidence of enuresis in patients taking risperidone, olanzapine or quetiapine is unknown.
Aims
To compare nocturnal enuresis in patients taking clozapine with that in patients taking risperidone, olanzapine or quetiapine.

\section{Method}
Observational cohort study using prescription event monitoring methods. Patients prescribed atypical antipsychotic medicines were followed up by questionnaires that were sent to their medical practitioner. Practitioners were asked to directly ask their patients about bed-wetting.

\section{Results}

Nocturnal enuresis was reported by 17 of $82(20.7 \%)$ patients taking clozapine, 11 of 115 (9.6\%) taking olanzapine, 7 of 105 (6.7\%) taking quetiapine and 12 of 195 (6.2\%) taking risperidone. Compared with clozapine, the risk of nocturnal enuresis was significantly lower in patients taking olanzapine (odds ratio, $\mathrm{OR}=0.43,95 \% \mathrm{Cl} 0.19-0.96$ ), quetiapine

$(\mathrm{OR}=0.33,95 \% \mathrm{Cl} 0.13-0.59)$ or risperidone $(\mathrm{OR}=0.27$, $0.12-0.59)$, with odds ratios adjusted for age, gender and duration of treatment.

\section{Conclusions}

Approximately one in five patients prescribed clozapine experienced bed-wetting. This was significantly higher than the rate of nocturnal enuresis in patients taking olanzapine, quetiapine or risperidone.

\section{Declaration of interest}

None.
Nocturnal enuresis or bed-wetting is one of the lesser known sideeffects of the atypical antipsychotic clozapine. Although case reports have been published since the $1990 \mathrm{~s},{ }^{1-3}$ the proportion of patients taking clozapine who experience nocturnal enuresis has not been accurately established, with previous estimates ranging from less than $1 \%{ }^{4}$ to as high as $42 \%{ }^{5}$ There have also been published case reports of enuresis with risperidone $e^{6,7}$ and urinary incontinence with olanzapine, ${ }^{8}$ but there have been no studies specifically designed to compare rates of nocturnal enuresis in patients taking atypical antipsychotic medicines.

During the monitoring of four atypical antipsychotics in New Zealand, the Intensive Medicines Monitoring Programme (IMMP) received several reports of nocturnal enuresis associated with clozapine. Assessment of these cases suggested a strong causal relationship, but it was not possible to determine an incidence rate from these spontaneous reports. Bed-wetting is likely to be underdetected by routine post-marketing pharmacovigilance methods, as has been demonstrated in clinical studies. ${ }^{9}$ Therefore, a cohort study was designed using intensive follow-up to determine more accurately the rates of nocturnal enuresis in patients taking clozapine and other atypical antipsychotics.

\section{Method}

The methods used by the IMMP to perform post-marketing safety studies have been described in detail previously. ${ }^{10}$ Essentially, cohort studies of selected medicines are conducted using prescription event monitoring in which cohorts of patients prescribed monitored medicines are established directly from pharmacy dispensing data. Adverse clinical events are subsequently identified from follow-up questionnaires sent to patients' doctors. These methods were adapted to perform this study of nocturnal enuresis in patients prescribed atypical antipsychotics.

\section{Establishing the study cohort}

Prescription data for the atypical antipsychotics clozapine, olanzapine, risperidone and quetiapine were returned from pharmacies throughout New Zealand directly to the IMMP in the usual way. ${ }^{10}$ For this enuresis study, the cohort was established from dispensing data from one urban district (Dunedin, in the South Island of New Zealand) in order to facilitate the intensive follow-up required. Data were entered for all Dunedin patients dispensed clozapine, olanzapine, risperidone or quetiapine between 1 August and 30 November 2004. Information collected from the dispensing data included patient details, information regarding atypical antipsychotics dispensed during this period and details of the prescribing doctor. Patients without an identifiable doctor or who had died during the period between prescription and follow-up were excluded from the final cohort. Patients aged less than 15 years or greater than 64 years were also excluded, as childhood enuresis and incontinence in the elderly could affect the results.

\section{Questionnaire design}

The follow-up questionnaire for this study was based on the routine IMMP questionnaire, on which doctors are asked to report all new clinical events for an individual since starting treatment. ${ }^{10}$ The IMMP questionnaire also asks whether treatment continues or the date and reason for stopping. For this study, questions about the indication for use of the atypical antipsychotic, the date treatment started, the dose once stabilised, and concomitant medications were also included. Four additional 
questions specifically enquired about nocturnal enuresis (including childhood enuresis) and a further question enquired about leakage of urine during the day (to assist in distinguishing nocturnal enuresis from other types of incontinence). In the covering letter on the front of the questionnaire, we requested that practitioners ask their patients the urinary/enuresis questions directly wherever possible.

\section{Follow-up procedure}

Follow-up questionnaires were given to doctors in November 2005. Those for psychiatrists or mental health nurses to complete were hand-delivered by researchers to encourage participation. Questionnaires were posted or delivered to general practitioners, with researchers again making personal contact whenever possible. If the doctor identified was not able to complete the questionnaire for a particular patient, they were asked to suggest an alternative practitioner to whom the IMMP could forward the questionnaire.

\section{Clinical assessment}

All questionnaires returned with clinical information were assessed by medically qualified staff at the IMMP. Adverse events reported were coded using terms from a specialised dictionary based on World Health Organization Adverse Reaction Terminology ${ }^{11}$ and causality assessment was performed to determine the relationship with the medicine. ${ }^{12}$ Urinary adverse events identified from the five additional questions were coded according to the above principles. A specific standard operating procedure was developed for coding urinary events in this study, in order to distinguish pre-existing urinary problems from new events since starting the medicine.

\section{Analyses}

Rates of nocturnal enuresis for each medicine were calculated using the number of 'new' cases (i.e. enuresis since starting the medicine) as the numerator and the population for whom a follow-up questionnaire was returned to the IMMP (the 'responder population') as the denominator. Patients identified as having nocturnal incontinence before starting the antipsychotic were excluded from these analyses. Confidence intervals (CIs) were calculated around the estimates and comparisons between medicines were made by calculating odds ratios (ORs), with clozapine as the reference medicine. A logistic regression model was used to calculate the ORs and $95 \%$ CIs and to adjust the estimates for the effects of the antipsychotic medicines on nocturnal enuresis according to age, gender and duration of treatment. Nothing else has been consistently related to nocturnal enuresis. These models accounted for the fact that some patients were in the data-set twice, because they took more than one antipsychotic (either concomitantly or consecutively) during the study period.

To identify potential risk factors for bed-wetting while taking an antipsychotic, analyses were performed to compare patients with new enuresis since starting the medicine with those patients who did not experience bed-wetting. For these analyses, the 'nonbed-wetting' group was defined as those patients in the responder population who did not answer 'yes' to a question asking whether bed-wetting had occurred while taking the medicine. This group also excluded all patients identified as having incontinence which pre-dated the atypical antipsychotic prescription. The patient group defined as having had childhood enuresis only included patients who had responded 'yes' to this question.

\section{Ethical approval}

The IMMP is a long-standing national medicines surveillance programme and its processes and practices have been approved by the New Zealand Privacy Commissioner. This study was carried out under the existing and ongoing IMMP ethical approval granted by the Otago Ethics Committee (reference OTA/04/32/CPD).

\section{Results}

Between 1 August and 30 November 2004, 979 patients were prescribed clozapine, olanzapine, risperidone or quetiapine. Of these, 881 patients had identifying information available, including date of birth. There were 612 patients aged 15-64 years at the time of first prescription in this period. Six patients were excluded - two patients had no identifiable doctor and four patients had died - and therefore the total study cohort consisted of 606 patients: 327 (54\%) were male and 279 (46\%) were female.

Table 1 shows the patient characteristics in each medicine group. Risperidone was the most frequently prescribed antipsychotic, with $42 \%$ of the study population receiving a prescription. Similar proportions of patients received prescriptions for olanzapine and quetiapine $(22.5 \%$ and $21.3 \%$ respectively), and about $14 \%$ of the cohort received a prescription for clozapine (Table 1).

The indication for use of an antipsychotic was reported for 366 patients ( $60 \%$ of cohort, $72 \%$ of questionnaires returned), with 310 patients having one indication reported and 56 having two. A summary of the first reported indications for these 366 patients is shown in Table 2. The most frequently reported diagnoses were schizophrenia and related disorders (63\% of first indications reported), with mood disorders representing about a fifth $(21 \%)$ of the indications reported.

A total of 642 questionnaires were sent out for 606 patients in the study cohort, with 36 patients completing two questionnaires (for two different antipsychotics prescribed during the study

\begin{tabular}{|c|c|c|c|c|c|}
\hline & $\begin{array}{l}\text { Mean age }{ }^{a} \\
\text { Years }\end{array}$ & $\begin{array}{l}\text { Male } \\
n(\%)\end{array}$ & $\begin{array}{c}\text { Female } \\
n(\%)\end{array}$ & $\begin{array}{l}\text { Number } \\
\text { of patients }\end{array}$ & $\begin{array}{c}\text { Proportion of study } \\
\text { cohort, \% }\end{array}$ \\
\hline Clozapine & 39.1 & $55(60)$ & $36(40)$ & 91 & 14.2 \\
\hline Olanzapine & 39.8 & $98(68)$ & $47(32)$ & 145 & 22.5 \\
\hline Quetiapine & 40.0 & $55(40)$ & $82(60)$ & 137 & 21.3 \\
\hline Risperidone & 41.5 & $137(51)$ & $133(49)$ & 270 & 42.0 \\
\hline Total & & 345 & 298 & $643^{b}$ & 100 \\
\hline
\end{tabular}


Table 2 Reported first indication for use of atypical antipsychotic medicine

\begin{tabular}{|c|c|c|c|}
\hline & $\begin{array}{l}\text { ICD-10 } \\
\text { codes }\end{array}$ & $\begin{array}{l}\text { Reports } \\
n\end{array}$ & $\begin{array}{l}\text { Proportion }^{\mathrm{a}} \\
\%\end{array}$ \\
\hline \multirow{5}{*}{$\begin{array}{l}\text { Schizophrenia and related disorders } \\
\text { Schizophrenia } \\
\text { Schizoaffective disorder } \\
\text { Unspecified psychosis } \\
\text { Persistent delusional disorder }\end{array}$} & \multirow[t]{5}{*}{ F20.0-29.0 } & 231 & \multirow[t]{5}{*}{63} \\
\hline & & 161 & \\
\hline & & 22 & \\
\hline & & 36 & \\
\hline & & 12 & \\
\hline \multirow{5}{*}{$\begin{array}{l}\text { Mood (affective) disorders } \\
\text { Bipolar affective disorder } \\
\text { Mania/hypomania } \\
\text { Depression } \\
\text { Unspecified affective disorder }\end{array}$} & \multirow[t]{5}{*}{ F30.0-39.0 } & 77 & \multirow[t]{5}{*}{21} \\
\hline & & 42 & \\
\hline & & 2 & \\
\hline & & 26 & \\
\hline & & 7 & \\
\hline \multirow{5}{*}{$\begin{array}{l}\text { Neurotic disorders } \\
\text { Anxiety disorders } \\
\text { Post-traumatic stress disorder } \\
\text { Obsessive-compulsive disorders } \\
\text { Somatisation disorder }\end{array}$} & \multirow[t]{5}{*}{ F40.0-48.0 } & 20 & \multirow[t]{5}{*}{5} \\
\hline & & 8 & \\
\hline & & 8 & \\
\hline & & 3 & \\
\hline & & 1 & \\
\hline Personality disorders & F60.0-69.0 & 10 & 3 \\
\hline Mental retardation & F70.0-79.0 & 9 & 2.5 \\
\hline Organic mental disorder & F00-F09 & 3 & 1.0 \\
\hline Pervasive development disorders & F80.0-F89.0 & 9 & 2.5 \\
\hline Conduct disorders & F91.1-91.9 & 3 & 1.0 \\
\hline \multirow{4}{*}{$\begin{array}{l}\text { Other disorders } \\
\text { Non-organic sleep disorder } \\
\text { Puerpural mental disorder } \\
\text { Tardive dyskinesia }^{\mathrm{b}}\end{array}$} & \multirow[t]{4}{*}{ F50-59 } & 4 & \multirow[t]{4}{*}{1.0} \\
\hline & & 2 & \\
\hline & & 1 & \\
\hline & & 1 & \\
\hline \multicolumn{2}{|l|}{ Total } & 366 & 100 \\
\hline \multicolumn{4}{|c|}{$\begin{array}{l}\text { a. Proportion of } 366 \text { first indications reported. } \\
\text { b. Interpreted as the patient experienced tardive dyskinesia on a previous } \\
\text { antipsychotic medicine, as this is not a recognised indication for these medicines. }\end{array}$} \\
\hline
\end{tabular}

period). A final total of 508 questionnaires were received by the IMMP, giving an overall response rate of $79 \%$. The response rates for each medicine were: clozapine 92\%, olanzapine $80 \%$, quetiapine $77 \%$ and risperidone $75 \%$.

\section{Risk of nocturnal enuresis}

A total of 52 patients reported bed-wetting while taking an antipsychotic. Of these patients, 11 were assessed as having nocturnal incontinence which pre-dated the antipsychotic and these patients were excluded from further analyses. Most were patients with intellectual disability who had continual (day and night) incontinence. The remaining 41 patients had experienced nocturnal enuresis since starting the atypical antipsychotic. Of these, six experienced enuresis with two antipsychotics.

Occurrence rates of nocturnal enuresis for each medicine are shown in Table 3. The six patients who experienced nocturnal enuresis while taking more than one antipsychotic were included in more than one medicine group. Patients taking olanzapine, quetiapine or risperidone had a significantly lower risk of nocturnal enuresis compared with patients taking clozapine (Table 3). Further testing showed that the risks of nocturnal enuresis for olanzapine, quetiapine and risperidone were not significantly different from each other. Adjustment for age, gender and duration of treatment resulted in only minor changes in the risk estimates (Table 3).

The question 'How often has the bed-wetting occurred while taking the medicine?' was answered by 37 (90\%) of the 41 patients with nocturnal enuresis since starting the atypical antipsychotic. Of these patients, 7 (19\%) reported experiencing nocturnal enuresis only once, $6(16 \%)$ twice and $24(65 \%)$ responded that it had occurred on multiple occasions.

\section{Risk factors for enuresis}

Of the 41 patients who experienced nocturnal enuresis, 10 (24\%) had received a prescription for a second atypical antipsychotic during the study period. Of 432 patients in the responder population who did not experience enuresis, only $18(4 \%)$ patients received a prescription for a second antipsychotic during the study period. This difference was highly significant $(P<0.0005)$.

A history of childhood enuresis was reported by 116 (27\%) of the 434 patients who responded to the question about this. In the nocturnal enuresis group (47 responses), 20 (43\%) reported having experienced childhood bed-wetting. Of the 450 responses from patients who did not have enuresis during treatment, only $90(20 \%)$ reported childhood enuresis. This difference was significant $(P=0.009)$. The results of further analyses for each individual medicine are shown in Table 4.

Of the 508 responses received in this study, 380 (75\%) stated that the patient was taking other prescribed medicines. For patients taking clozapine, the number of concomitant medicines ranged from 1 to 8 , for olanzapine from 1 to 9 , for quetiapine from 1 to 10 (with one other patient on 20 concomitant medicines) and for risperidone from 1 to 13 medicines. The majority $(71 \%)$ of concomitant medicines reported were central nervous system (CNS) medicines (Anatomical Therapeutic Classification group N (www.whocc.no/atc_ddd_index)). In the clozapine group, $62 \%$ (of those for whom a questionnaire was completed) were also taking other CNS medicines. For olanzapine and quetiapine, $70 \%$ of each patient group was also taking other CNS medicines and for risperidone the figure was $69 \%$. The differences between the proportions of patients in each group also taking other CNS medicines were not statistically significant $(P=0.705)$.

\section{Discussion}

The key finding of this study was that approximately one in five patients between 15 and 64 years of age taking clozapine experienced

\begin{tabular}{|c|c|c|c|c|}
\hline & $\begin{array}{l}\text { Number with } \\
\text { enuresis }^{a}\end{array}$ & $\begin{array}{l}\text { Percentage with } \\
\text { enuresis }(95 \% \mathrm{Cl})\end{array}$ & $\begin{array}{l}\text { Unadjusted odds } \\
\text { ratio }(95 \% \mathrm{Cl})\end{array}$ & $\begin{array}{l}\text { Adjusted odds ratio }{ }^{b} \\
\qquad(95 \% \mathrm{Cl})\end{array}$ \\
\hline Clozapine $(n=82)^{c}$ & 17 & $20.7(12.6-31.1)$ & 1 (reference) & 1 (reference) \\
\hline Olanzapine $(n=115)^{\mathrm{c}}$ & 11 & $9.6(4.9-16.5)$ & $0.41(0.19-0.91)$ & $0.43(0.19-0.96)$ \\
\hline Quetiapine $(n=105)^{c}$ & 7 & $6.7(2.7-13.3)$ & $0.28(0.11-0.72)$ & $0.33(0.13-0.59)$ \\
\hline Risperidone $(n=195)^{c}$ & 12 & $6.2(3.2-10.5)$ & $0.25(0.12-0.53)$ & $0.27(0.12-0.59)$ \\
\hline
\end{tabular}


Table 4 Risk of enuresis according to whether patients reported childhood enuresis

\begin{tabular}{|c|c|c|c|c|c|c|c|c|c|c|c|c|}
\hline & \multicolumn{3}{|c|}{ Clozapine } & \multicolumn{3}{|c|}{ Olanzapine } & \multicolumn{3}{|c|}{ Quetiapine } & \multicolumn{3}{|c|}{ Risperidone } \\
\hline & $\begin{array}{c}\text { New } \\
\text { enuresis }\end{array}$ & $\begin{array}{c}\text { No } \\
\text { enuresis }\end{array}$ & $\begin{array}{c}\mathrm{OR}^{\mathrm{a}} \\
(95 \% \mathrm{Cl})\end{array}$ & $\begin{array}{c}\text { New } \\
\text { enuresis }\end{array}$ & $\begin{array}{c}\text { No } \\
\text { enuresis }\end{array}$ & $\begin{array}{c}\mathrm{OR}^{\mathrm{a}} \\
(95 \% \mathrm{Cl})\end{array}$ & $\begin{array}{c}\text { New } \\
\text { enuresis }\end{array}$ & $\begin{array}{c}\text { No } \\
\text { enuresis }\end{array}$ & $\begin{array}{c}\mathrm{OR}^{\mathrm{a}} \\
(95 \% \mathrm{Cl})\end{array}$ & $\begin{array}{l}\text { New } \\
\text { enuresis }\end{array}$ & $\begin{array}{c}\text { No } \\
\text { enuresis }\end{array}$ & $\begin{array}{c}\mathrm{OR}^{\mathrm{a}} \\
(95 \% \mathrm{Cl})\end{array}$ \\
\hline $\begin{array}{l}\text { Childhood } \\
\text { enuresis, } n\end{array}$ & 6 & 17 & $\begin{array}{c}1.52 \\
(0.44-5.38) \\
\end{array}$ & 4 & 25 & $\begin{array}{c}1.53 \\
(0.38-6.10) \\
\end{array}$ & 3 & 18 & $\begin{array}{c}4.05 \\
(0.56-29.20) \\
\end{array}$ & 7 & 30 & $\begin{array}{c}6.19 \\
(1.61-23.88) \\
\end{array}$ \\
\hline $\begin{array}{l}\text { Without childhood } \\
\text { enuresis, } n\end{array}$ & 8 & 40 & & 6 & 55 & & 4 & 57 & & 5 & 153 & \\
\hline
\end{tabular}

bed-wetting while taking this medicine. This estimate was significantly higher than the risk of nocturnal enuresis reported with the other antipsychotics included in this study. Adjustment for age, gender and duration of treatment did not change these results. The occurrence of bed-wetting reported with risperidone $(6.2 \%)$, olanzapine $(9.6 \%)$ and quetiapine $(6.7 \%)$ were all higher than the background occurrence of nocturnal enuresis in non-institutionalised adults, which has been estimated at $0.5 \% .^{13}$

\section{Previous estimates}

Previous estimates of the occurrence of nocturnal enuresis in patients on clozapine have come from various sources. A letter to a journal citing unpublished pharmaceutical company data stated that nocturnal enuresis occurred in less than $1 \%$ of individuals taking clozapine. ${ }^{4}$ If the company's estimate was derived using spontaneous reports as the numerator and clozapine sales data as the denominator, it is likely to be a gross underestimate because enuresis is an underreported adverse event. ${ }^{9}$ A clinical pharmacology study of 44 patients reported enuresis as a 'late' side-effect in $27 \%$ of patients taking clozapine, ${ }^{14}$ while another study of 57 in-patients treated with clozapine reported that $16(28 \%)$ developed urinary incontinence (type unspecified). ${ }^{15}$ The in-patients in the latter study might not be representative of the majority of patients taking atypical antipsychotic medicines, who are now more likely to be treated in the community. ${ }^{16}$

In a more recent study, 103 patients were interviewed about all side-effects during clozapine maintenance treatment and although only 1 patient admitted to bed-wetting on general questioning, direct questioning elicited that $40(39 \%)$ patients had experienced nocturnal enuresis. ${ }^{9}$ This demonstrates the importance of using a specific questionnaire to ask patients directly about urinary symptoms, as was done in our study. The highest previous estimate of $42 \%$ was derived from a small study of patients identified through the UK Clozaril Patient Monitoring Service (CPMS), who were interviewed about their first 3 months of clozapine treatment. ${ }^{5}$ Retrospective assessment identified that 5 of 12 patients included in this study experienced nocturnal incontinence. Interestingly, the enuresis resolved in all five after 3 months despite continuing clozapine treatment.

\section{Strengths and limitations}

Our study was not restricted to the first months of treatment and included some patients who had been taking atypical antipsychotic medicines for long periods. It is possible that our population included patients who had experienced initial bedwetting which had resolved and was not reported. Moreover, some patients who had experienced enuresis might have stopped using clozapine and thus have avoided inclusion in this study. Therefore the rate of $21 \%$ calculated in the IMMP study could be an underestimate. However, perhaps more importantly, the small sample size of the CPMS study ${ }^{5}$ and most of the other previous studies means there is a wide degree of uncertainty surrounding earlier estimates.

The results of our intensive monitoring study may more accurately reflect the occurrence of nocturnal enuresis with 'reallife' use of atypical antipsychotics compared with risk estimates derived from clinical trials. The patient population in the IMMP study is more generally representative as very few patients were excluded, with cohorts established directly from pharmacy dispensing data. A further strength of this study was the intensive follow-up of patients through their mental healthcare teams, while the high response rate achieved reduced the possible effect of responder bias. As response rates depended on the cooperation of clinicians rather than patients, the higher response rate for the clozapine group was unlikely to be related to differences in the occurrence of enuresis. Clinicians were requested to directly ask patients specific questions relating to nocturnal enuresis and this should have reduced the likelihood of underreporting. It is still possible that some cases of bed-wetting were not identified. However, as there were not likely to be differences in reporting rates of enuresis among the four medicines, this should not have affected the odds ratios.

Our study is the first specifically designed to compare rates of nocturnal enuresis in patients aged 15-64 taking different atypical antipsychotics. Although rates of 'incontinence/nocturia' were reported for patients taking olanzapine $(1 \%)$, risperidone $(3 \%)$ and quetiapine $(4 \%)$ in one clinical trial, ${ }^{17}$ this study was primarily designed to determine the effectiveness of these medicines and reporting of all adverse events was a secondary aim. Another randomised controlled trial reported rates of enuresis in adolescent patients with early-onset schizophrenia taking clozapine $(56 \%)$ or olanzapine $(29 \%) .{ }^{18}$ As with other clinical trials, that study was conducted in a small and select population, the primary aim was to assess efficacy and the study period was relatively short (12 weeks). Our larger IMMP study may more accurately estimate the rates of enuresis in patients taking atypical antipsychotics in 'real-life' conditions over a longer time period.

Our study suggests that prescription of a second atypical antipsychotic increased the occurrence of bed-wetting. This finding is not unexpected and concomitant antipsychotic treatment is a recognised issue as some patients may require more than one medicine under certain circumstances. ${ }^{19}$ There was no evidence that prescription of other concomitant CNS medicines could explain the higher rate of enuresis in patients on clozapine in our study, as there was no significant difference in the proportion prescribed a concomitant CNS medicine in each treatment group.

\section{Possible mechanisms}

The mechanism by which atypical antipsychotics may cause nocturnal enuresis remains unclear. $^{15,20}$ Maintenance of 
continence involves multiple physiological systems and several of them could be affected by antipsychotics. ${ }^{5}$ Anticholinergic properties could inhibit detrusor contraction, leading to retention of urine with overflow, and anti-adrenergic activity could decrease bladder sphincter tone. ${ }^{5}$ In anaesthetised rats, clozapine, olanzapine and risperidone were noted to alter urodynamics, resulting in reduced activity of the external urethral sphincter. ${ }^{21,22}$ These effects were proposed to involve central actions. ${ }^{22}$ Nonspecific actions of clozapine such as sedation and lowering of the seizure threshold could also contribute. ${ }^{5,20}$ Drug-induced diabetes mellitus could result in polyuria, which could lead to nocturnal incontinence ${ }^{20}$ and there have also been case reports of diabetes insipidus with clozapine. ${ }^{23}$ Drug-induced diabetes insipidus is generally considered to be nephrogenic. ${ }^{23}$ A case of polyuria following olanzapine overdose was reported, with laboratory results supporting the diagnosis of diabetes insipidus and with intravenous desmopressin resulting in rapid resolution of the polyuria. ${ }^{24}$ This led the authors to propose a central rather than nephrogenic origin for the diabetes insipidus. Antipsychoticinduced enuresis has been reported to respond to numerous pharmacological strategies. ${ }^{1,2,4,15}$ The mechanism may be multifactorial in view of the broad actions of antipsychotics ${ }^{2}$ and further research is required.

\section{Clinical implications}

In summary, this study of the 'real-life' use of atypical antipsychotics showed that bed-wetting is relatively common, with about $21 \%$ of patients on clozapine (and around $10 \%$ of patients on other atypical antipsychotic medicines) likely to suffer this unpleasant and embarrassing adverse effect. Although not lifethreatening, nocturnal enuresis may have a profound impact on patients (and their family/carers) and a further consequence may be non-adherence with treatment, with an associated deterioration in quality of life. ${ }^{25}$ Mental health practitioners should ask patients directly about bed-wetting in order to identify this and discuss management options. Appropriate risk management need not necessarily involve cessation of the antipsychotic. There have been reports of successful treatment of clozapine-induced enuresis with oxybutynin, ${ }^{1}$ amitriptyline, ${ }^{2}$ desmopressin ${ }^{4}$ and ephedrine. ${ }^{15}$ Other management strategies might include dose reduction where possible, or practical measures such as advising patients to limit fluid intake during the evening and to empty their bladder before going to sleep. Increased awareness of bed-wetting as a common side-effect of atypical antipsychotics should lead to improved care of these patients.

\footnotetext{
Mira Harrison-Woolrych, BM, DM, FRCOG, Department of Preventive and Social Medicine; Keren Skegg, MB, FRCPsych, Department of Psychological Medicine; Janelle Ashton, Peter Herbison, MSc, Department of Preventive and Social Medicine; David C. G. Skegg, MB, DPhil, Vice Chancellor, University of Otago, New Zealand

Correspondence: Dr Mira Harrison-Woolrych, Director, Intensive Medicines Monitoring Programme, Department of Preventive and Social Medicine, University of Otago, PO Box 913, Dunedin 9054, New Zealand. Email: Mira.harrison-woolrych@otago.ac.nz

First received 20 Sep 2010, final revision 8 Feb 2011, accepted 28 Feb 2011
}

\section{Funding}

This study was funded by the NZ Ministry of Health (Medsafe) and the University of Otago (IMMP Research Fund).

\section{Acknowledgements}

We would like to thank all the doctors, nurses and other members of the Dunedin mental health teams who helped us gain follow-up information for the patients in this study. We also gratefully acknowledge the patients for their valuable contribution to this work.
Special thanks to Anita Admiraal, Postgraduate Coordinator in the Department of Psychological Medicine for all her assistance. We also acknowledge former IMMP medical assessors, Dr Rachael McLean and Dr Jenny Clifton, who undertook clinical assessments of the follow-up questionnaires, and Lifeng Zhou, who assisted with some of the statistical analyses. Thanks also to the IMMP team, especially Kaylene Crawford and Elizabeth Watson.

All authors of this paper had access to the raw data collected in this study and take full responsibility for the material included in this paper.

\section{References}

1 Frankenburg F, Kando JC, Centorrino F, Gilbert J. Bladder dysfunction associated with clozapine therapy. J Clin Psychiatry 1996; 57: 39-40.

2 Praharaj SK, Arora M. Amitryptyline for clozapine-induced nocturnal enuresis and sialorrhoea. Br J Clin Pharmacol 2006; 63: 128-9.

3 Lee MJ, Kim CE. Use of aripiprazole in clozapine induced enuresis: report of two cases. J Korean Med Sci 2010; 25: 333-5.

4 Aronowitz J, Safferman A, Lieberman J. Management of clozapine-induced enuresis. Am J Psychiatry 1995; 152: 472.

5 Warner JP, Harvey CA, Barnes TR. Clozapine and urinary incontinence. Int Clin Psychopharmacol 1994; 9: 207-9.

6 Agarwal V. Urinary incontinence with risperidone. J Clin Psychiatry 2000; 61: 219.

7 Kantrowitz JT, Srihari VH, Tek C. Three cases of risperidone-induced enuresis. Schizophr Res 2006; 84: 174-5.

8 Vernon LT, Fuller MA, Hattab H, Varnes KM. Olanzapine-induced urinary incontinence: treatment with ephedrine. J Clin Psychiatry 2000; 61: 601-2.

9 Yusufi B, Mukherjee S, Flanagan R, Paton C, Dunn G, Page E, et al. Prevalence and nature of side effects during clozapine maintenance treatment and the relationship with clozapine dose and plasma concentration. Int Clin Psychopharmacol 2007; 22: 238-43.

10 Harrison-Woolrych M, Coulter DM. PEM in New Zealand. In Pharmacovigilance (eds R Mann, E Andrews): 317-32. John Wiley \& Sons, 2007.

11 Edwards I, Biriell C. WHO Programme - global monitoring. In Pharmacovigilance (eds R Mann, E Andrews): 151-66. John Wiley \& Sons, 2002.

12 Karch FE, Lasagna L. Adverse drug reactions. A critical review. JAMA 1975; 234: 1236-41.

13 Hirasing RA, van Leerdam FJM, Bolk-Bennink L, Janknegt RA. Enuresis nocturna in adults. Scand J Urol Nephrol 1997; 31: 533-6.

14 Centorrino F, Baldessarini RJ, Kando JC, Frankenburg FR, Volpicelli SA, Flood JG. Clozapine and metabolites: concentrations in serum and clinical findings during treatment of chronically psychotic patients. J Clin Psychopharmacol 1994; 14: 119-25.

15 Fuller MA, Borovicka MC, Jaskiw GE, Simon MR, Kwon K, Konicki PE. Clozapine-induced urinary incontinence: incidence and treatment with ephedrine. J Clin Psychiatry 1996; 57: 514-8.

16 Thornicroft G, Tansella M. Components of a modern mental health service: a pragmatic balance of community and hospital care. Overview of systematic evidence. Br J Psychiatry 2004; 185: 283-90.

17 Stroup TS, Lieberman JA, McEvoy JP, Swartz MS, Davis SM, Rosenheck RA, et al. Effectiveness of olanzapine, quetiapine, risperidone and ziprasidone in patients with chronic schizophrenia following discontinuation of a previous atypical antipsychotic. Am J Psychiatry 2006; 163: 611-22.

18 Kumra S, Kranzler H, Gerbino-Rosen G, Kester HM, DeThomas C, Kafantaris V, et al. Clozapine and 'high-dose' olanzapine in refractory early-onset schizophrenia: a 12 week randomized and double-blind comparison. Biol Psychiatry 2008; 63: 524-9.

19 Correll CU, Rummel-Kluge C, Corves C, Kane JM, Leucht S. Antipsychotic combinations vs monotherapy in schizophrenia: a meta-analysis of randomized controlled trials. Schizophr Bull 2009; 35: 443-57.

$20 \mathrm{Kho} \mathrm{KH}$, Nielsen O. Clozapine-induced nocturnal enuresis: diagnostic and treatment issues. Psychiatr Bull 2001; 25: 232-3.

21 Vera $\mathrm{PL}$, Nadelhaft I. Clozapine inhibits micturition parameters and the external urethral sphincter during cystometry in anaesthetized rats. Brain Res 2001; 901: 219-29.

22 Vera PL, Miranda-Sousa A, Nadelhaft I. Effects of two atypical neuroleptics, olanzapine and risperidone, on the function of the urinary bladder and the external urethral sphincter in anaesthetized rats. BMC Pharmacol 2001; 1: 4.

23 Bendz H, Aurell M. Drug-induced diabetes insipidus. Drug Saf 1999; 21: 449-56.

24 Etienne L, Wittebole $\mathrm{X}$, Liolios A, Hantson P. Polyuria after olanzapine overdose. Am J Psychiatry 2004; 161: 1130.

25 Safferman A, Lieberman JA, Kane JM, Szymanski S, Kinon B. Update on the clinical efficacy and side effects of clozapine. Schizophr Bull 1991; 17: 247-61. 